\title{
Erratum to: Actinomucor elegans var. kuwaitiensis isolated from the wound of a diabetic patient
}

\author{
Zia U. Khan · Suhail Ahmad • Eiman Mokaddas • \\ Rachel Chandy $\cdot$ Josep Cano $\cdot$ Josep Guarro
}

Published online: 24 July 2013

(C) Springer Science+Business Media Dordrecht 2013

Erratum to: Antonie van Leeuwenhoek (2008)

94:343-352

DOI 10.1007/s10482-008-9251-1

"In the original published article, the accession number AJ849557 in the Descriptio latine section is incorrect. The correct accession number is AJ849551."

The online version of the original article can be found under doi:10.1007/s10482-008-9251-1.

Z. U. Khan $(\varangle) \cdot$ S. Ahmad · E. Mokaddas $\cdot$ R. Chandy Department of Microbiology, Faculty of Medicine, Kuwait University, P.O. Box 24923, Safat 13110, Kuwait e-mail: zkhan@hsc.edu.kw

J. Cano · J. Guarro

Microbiology Unit, Medicine School, Rovira i Virgili

University, C/Santt Llorenc, 21, 43201 Reus, Spain 